\title{
Analisa Produktivitas Tertinggi dan Terbaik pada Penggunaan Lahan Pasar Genteng Baru Surabaya
}

\author{
Rintih Prastianing Atas Kasih dan Christiono Utomo \\ Jurusan Teknik Sipil, Fakultas Teknik Sipil dan Perencanaan, Institut Teknologi Sepuluh Nopember (ITS) \\ Jl. Arief Rahman Hakim, Surabaya 60111 Indonesia \\ E-mail: christiono@ce.its.ac.id ; rintih.kasih@gmail.com
}

\begin{abstract}
Abstrak- Salah satu ikon pusat perdagangan di Surabaya yaitu Pasar Genteng Baru dan merupakan salah satu tanah aset milik pemerintah kota yang strategis dan potensial untuk dikembangkan yang letaknya ditengah kota. Namun keberadaan lahan tersebut belum dimanfaatkan dengan maksimal. Sehingga pasar Genteng baru harus segera direvitalisasi. Analisa lahan Pasar Genteng Baru ini menggunakan metode Highest and Best Use (HBU). Analisis ini meliputi empat hal pokok yaitu analisis kelayakan secara fisik (physically feasible), analisis kelayakan secara peraturan (legally permissible), analisis kelayakan secara keuangan (financially feasible), dan analisis produktivitas yang maksimal (maximally productive). Dari hasil penelitian didapatkan alternatif yang menghasilkan nilai lahan tertinggi dan produktivitas maksimum adalah alternatif mix used pasar dengan hotel. Nilai lahan yang didapatkan sebesar Rp. $38.800 .905 / \mathrm{m}^{2}$ dengan produktivitas meningkat sebesar $123,77 \%$.

Baru

Kata kunci : Highest and Best Use, Lahan, Pasar Genteng
\end{abstract}

\section{LATAR BELAKANG}

K OTA Surabaya merupkan kota terbesar kedua dengan penduduk yang berjumlah besar. Hal ini memacu terjadinya perkembangan kota yang sangat dinamis. Perkembangan kota yang dinamis ditandai dengan munculnya pusat perdagangan. Salah satu ikon pusat perdagangan Kota Surabaya yang cukup pesat adalah Pasar Genteng Baru Kota Surabaya.

Pasar Genteng Baru Surabaya dengan luas lahan \pm $4367,205 \mathrm{~m}^{2}$ berada di dekat pusat kota Surabaya di jalan Genteng Besar, Genteng Surabaya dekat Kantor Kotamadya, Hotel tunjungan, Tunjungan Plaza dan Hotel Weta seperti pada Gambar 1. Namun hingga kini lahan tersebut belum dimanfaatkan secara optimal karena selama ini fasilitas yang tidak lengkap termasuk lahan parkir yang tidak tersedia dan infrastruktur penunjang lainnya serta kondisi belanja yang tidak nyaman karena kotor. Salah satu upaya yang dilakukan pemerintah kota untuk mengoptimalkan lahan Pasar Genteng Baru yaitu dengan rencana pembangunan/ revitalisasi Pasar Genteng Baru.

Dengan posisi berada ditengah kota Surabaya, maka beberapa alternatif pemanfaatan pada lahan Pasar Genteng Baru di kota Surabaya bisa dikembangkan. Pemanfaatan lahan tersebut perlu dikaji secara cermat. Dibutuhkan partisipasi seluruh elemen yang berperan sebagai pemangku kepentingan (stakeholder) yang akan bersentuhan langsung dengan fasilitas yang akan dibangun pada lokasi tersebut. Analisis Penggunaan Tertinggi dan Terbaik Highest and Best Use (HBU) merupakan penggunaan yang paling mungkin dan optimal dari suatu properti secara legal diijinkan, secara fisik memungkinkan, layak secara finansial, maupun produktivitas maksimum dengan memperoleh nilai lahan tertinggi [1]. Maka dipandang perlu untuk menentukan pemanfaatan yang terbaik untuk mengoptimalkan lahan Pasar Genteng Baru di Kota Surabaya dengan cara menggunakan metode analisa penggunaan tertinggi dan terbaik, dimana dengan analisa ini akan diperoleh jenis pemanfaatan lahan yang tidak sekedar layak untuk dibangun, tetapi merupakan pemanfaatan yang tertinggi sekaligus terbaik yang dapat dicapai oleh lahan. Sehingga perlu dilakukan penelitian mengenai analisa tertinggi dan terbaik pada lahan Pasar Genteng Baru di Kota Surabaya.

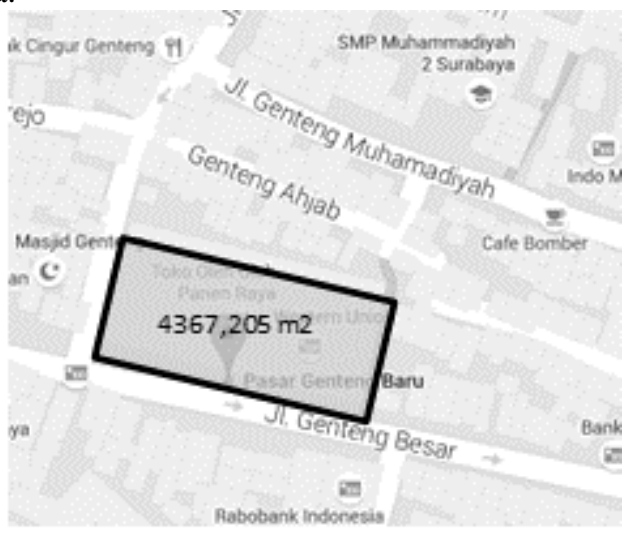

Gambar 1. Lokasi Objek Penelitian (Lahan Pasar Genteng Baru Surabaya)

\section{PENELITIAN TERDAHULU}

Penelitian terdahulu yang pernah dilakukan berkaitan dengan tema penelitian Highest and Best Use antara lain :Penelitian [2], dalam tugas akhirnya yang berjudul "Analisis Highest and Best Use lahan " $\mathrm{X}$ " untuk properti komersial " meneliti tentang Pemanfaatan lahan yang terbatas perlu dilakukan optimalisasi lahan menggunakan metode HBU ubtuk mengetahui alternatif apa yang akan dibangun diatasnya dengan nilai lahan tertinggi. Pemilihan alternatif berdasarkan hasil dari uji kelayakan dan pengamatan langsung di lokasi sekitar proyek dan adanya properti sejenis yang dibandingkan. Alternatif properti yang digunakan yaitu Apartemen, Hotel, Perkantoran, dan Pertokoan. Hasil analisa HBU Hotel merupakan alternatif penggunaan lahan terbaik. Lalu Penelitian [3], dalam tugas akhirnya yang berjudul "Analisa Highest and Best Use (HBU) pada lahan bekas SPBU Biliton Surabaya" meneliti tentang Alternatif properti komersial yang memberikan manfaat tertinggi untuk lahan bekas SPBU Biliton menggunakan metode HBU. Alternatif properti yang digunakan yaitu Pertokoan, Perkantoran, Pujasera dan Hotel. Hasil analisa HBU Pertokoan merupakan alternatif 
penggunaan lahan terbaik .Sedangkan Penelitian [4], dalam thesisnya yang berjudul "Analisa Peningkatan Nilai Penggunaan Lahan Pasar Keputran di Kota Surabaya" meneliti tentang Alternatif penggunaan yang memungkinkan untuk diterapkan di atas lahan Pasar Keputran. Alternatif properti yang digunakan yaitu pasar dan diversifikasi usaha pasar, pasar dan rumah susun sewa, serta pasar dan gedung parkir. Hasil analisa HBU diversifikasi usaha pasar merupakan alternatif penggunaan lahan terbaik

Berdasarkan keseluruhan penelitian tersebut diatas terdapat beberapa persamaan mendasar dengan penelitian terdahulu yaitu penelitian ini bertujuan untuk mendapatkan keputusan investasi properti terbaik dan persamaan dalam hal metode analisa yang digunakan yaitu menggunakan analisa pada aspek legal, fisik, finansial dan produktifitas maksimum. Sedangkan perbedaan penelitian terdahulu dengan penelitian pada Tugas Akhir ini berupa objek lahan yang diteliti. Pada penelitian [3] dan [4] objek lahan yang digunakan adalah lahan yang telah difungsikan menjadi bangunan berupa gedung SPBU dan pasar Keputran serta Penelitian [2] berupa lahan kosong. Sedangkan pada penelitian tugas akhir ini objek penelitian berupa lahan Pasar seperti pada penelitian[4], dimana bangunan sudah ada sebelumnya tetapi dianggap kosong. Pada analisa tugas akhir ini lahan objek penelitian direncanakan sebagai lahan kosong dikarenakan kondisi bangunan yang kurang terawat dengan baik dan kondisi yang tidak nyaman penuh sesak. Penelitian ini juga mempertimbangkan resiko politik yang dimungkinkan terjadi yaitu beruda proyek properti pemerintah dan merupakan fasilitas pelayanan dasar bagi masyarakat dan di sisi lain proyek properti ini juga dituntut untuk memberikan produktifitas maksimal dengan tetap mempertimbangkan ketentuan yang berlaku.

\section{METODOLOGI}

Penelitian ini menggunakan analisa pemanfaatan lahan pasar genteng Baru dengan menggunakan metode tertinggi dan terbaik (HBU).

\section{A. Model dan Konsep Penelitian}

Penelitian ini menggunakan prinsip penilaian penggunaan tertinggi dan terbaik (Highest and Best Use) untuk meghasilkan nilai tertinggi dari lahan pasar Genteng Baru

\section{B. Data Penelitian}

Data yang digunakan dalam penelitian berupa data primer dan sekunder. Data primer diperoleh melalui pengamatan langsung oleh peneliti, sedangkan data sekunder diperoleh dari berbagai sumber diantaranya dari PD. Pasar Surya, Dinas Tata Kota, PT. PLN, PDAM dan instansi-instansi lain yang terkait.

\section{Analisa Data}

Dari data-data yang terkumpul, dilakukan analisa legal, fisik, finansial dan produktivitas maksimum

1) Secara Hukum Diizinkan (Legally permissible)

Penilaian ini merupakan tahap seleksi untuk menentukan kegunaan-kegunaan yang diizinkan, meliputi Pembatasan secara pribadi, zoning, peraturan bangunan, peraturan lingkungan, ketentuan yang berkenaan dengan bangunan [5].

2) Secara Fisik Memungkinkan (Physically possible)
Dalam aspek fisik hal yang harus ditinjau adalah ukuran, kemiringan, terrain, aksesibilitas, resiko bencana alam, utilitas, drainase, sistem saluran limbah cair, topografi [1]. Serta bentuk, daerah, sarana public, desain dan kondisi [5].

3) Secara Finansial Layak (financially feasible)

Proses pengujian pada kriteria ini melibatkan beberapa analisis yang harus dilalui oleh sebuah alternatif yaitu: Biaya Investasi, Pendapatan, Pengeluaran, Aliran Kas, Net Present Value (NPV).

Net Present Value (NPV) menganalisa selisih benefit (Penerimaan) dengan Cost (pengeluaran) yang telah dipresent Valuekan. Apabila NPV >0 maka proyek dikatakan layak, sedangkan jika sebaliknya NPV $<0$ maka proyek dikatakan tidak layak.

$$
\begin{aligned}
\mathrm{NPV} & =-\mathrm{kt}+\frac{b 1-c 1}{(1+i)}+\frac{b 2-c 2}{(1+i)^{2}}+\ldots+\frac{b n-c n}{(1+i)^{n}} \\
& =\sum_{t=t}^{n} \frac{B t-C t-K t}{(1+i)^{t}}
\end{aligned}
$$

dimana :

kt merupakan capital yang digunakan pada periode investasi,

b1, b2, .., bn adalah penerimaan pada tahun ke-1 sampai dengan tahun ke $\mathrm{n}$,

$\mathrm{c} 1, \mathrm{c} 2, \ldots, \mathrm{cn}$ adalah pengeluaran pada tahunke 1 sampai dengan tahun ke $\mathrm{n}$, dan

i sama dengan tingkat discount rate.

4) Produktivitas maksimum

Merupakan penggunaan yang menghasilkan nilai residual yang tertinggi dan konsisten dengan tingkat pengembalian yang dijamin pasar [5].

Variabel penelitian dari analisa HBU dapat dilihat pada tabel 1 .

Tabel 1.

\begin{tabular}{|c|c|c|c|c|}
\hline No & Variabel & "Klasifikasi & Sumber Data & $\begin{array}{l}\text { Type } \\
\text { data }\end{array}$ \\
\hline 1 & $\begin{array}{l}\text { Penentua } \\
\mathrm{n} \\
\text { Alternati } \\
\mathrm{f}\end{array}$ & $\begin{array}{l}\text { Alternatif } \\
\text { penggunaan } \\
\text { lahan pada Pasar } \\
\text { Genteng Baru }\end{array}$ & $\begin{array}{l}\text { Wawancara dan } \\
\text { kuesioner }\end{array}$ & Primer \\
\hline 2 & $\begin{array}{l}\text { Aspek } \\
\text { Legal }\end{array}$ & $\begin{array}{l}\text { a. Zoning } \\
\text { b. Building code, } \\
\text { yaitu : } \\
\text { GSB, KDB, } \\
\text { KLB, KDH } \\
\text { dan } \\
\text { ketinggian } \\
\text { bangunan }\end{array}$ & $\begin{array}{l}\text { Dinas cipta karya } \\
\text { dan tata ruang }\end{array}$ & $\begin{array}{l}\text { Sekunde } \\
\mathrm{r}\end{array}$ \\
\hline 3 & $\begin{array}{l}\text { Aspek } \\
\text { Fisik }\end{array}$ & $\begin{array}{l}\text { a. Lokasi lahan/ } \\
\text { letak lahan } \\
\text { b. Bentuk dan } \\
\text { luas lahan } \\
\text { c. Akses ke } \\
\text { lokasi } \\
\text { d. Utilitas kota }\end{array}$ & $\begin{array}{l}\text { 1. Pengamatan } \\
\text { lahan } \\
\text { 2. Stakeholder } \\
\text { lahan }\end{array}$ & $\begin{array}{l}\text { Primer } \\
\text { dan } \\
\text { Sekunde } \\
\mathrm{r}\end{array}$ \\
\hline 4 & $\begin{array}{l}\text { Aspek } \\
\text { Finansial }\end{array}$ & $\begin{array}{l}\text { a. Biaya Investasi } \\
\text { b. Pendapatan } \\
\text { c. Pengeluaran } \\
\text { d. Aliran Kas }\end{array}$ & $\begin{array}{l}\text { 1. Data } \\
\text { Pembanding } \\
\text { 2. Perhitungan } \\
\text { 3. PT. PLN } \\
\text { (Persero) } \\
\text { 4. PDAM } \\
\text { Surabaya } \\
\text { 5. Data } \\
\quad \text { Pembanding }\end{array}$ & $\begin{array}{l}\text { Sekunde } \\
\mathrm{r}\end{array}$ \\
\hline
\end{tabular}

Variabel analisa HBU 


\begin{tabular}{lllll}
\hline \hline 5 & $\begin{array}{l}\text { Produkti } \\
\text { vitas } \\
\text { maksimu } \\
\mathrm{m}\end{array}$ & $\begin{array}{l}\text { Nilai lahan } \\
\text { tertinggi }\end{array}$ & Perhitungan & $\begin{array}{l}\text { Sekunde } \\
\mathrm{r}\end{array}$ \\
\hline Sumber : Analisa Penulis & & \\
\hline
\end{tabular}

Bagan Alir dapat dilihat pada Gambar 2.

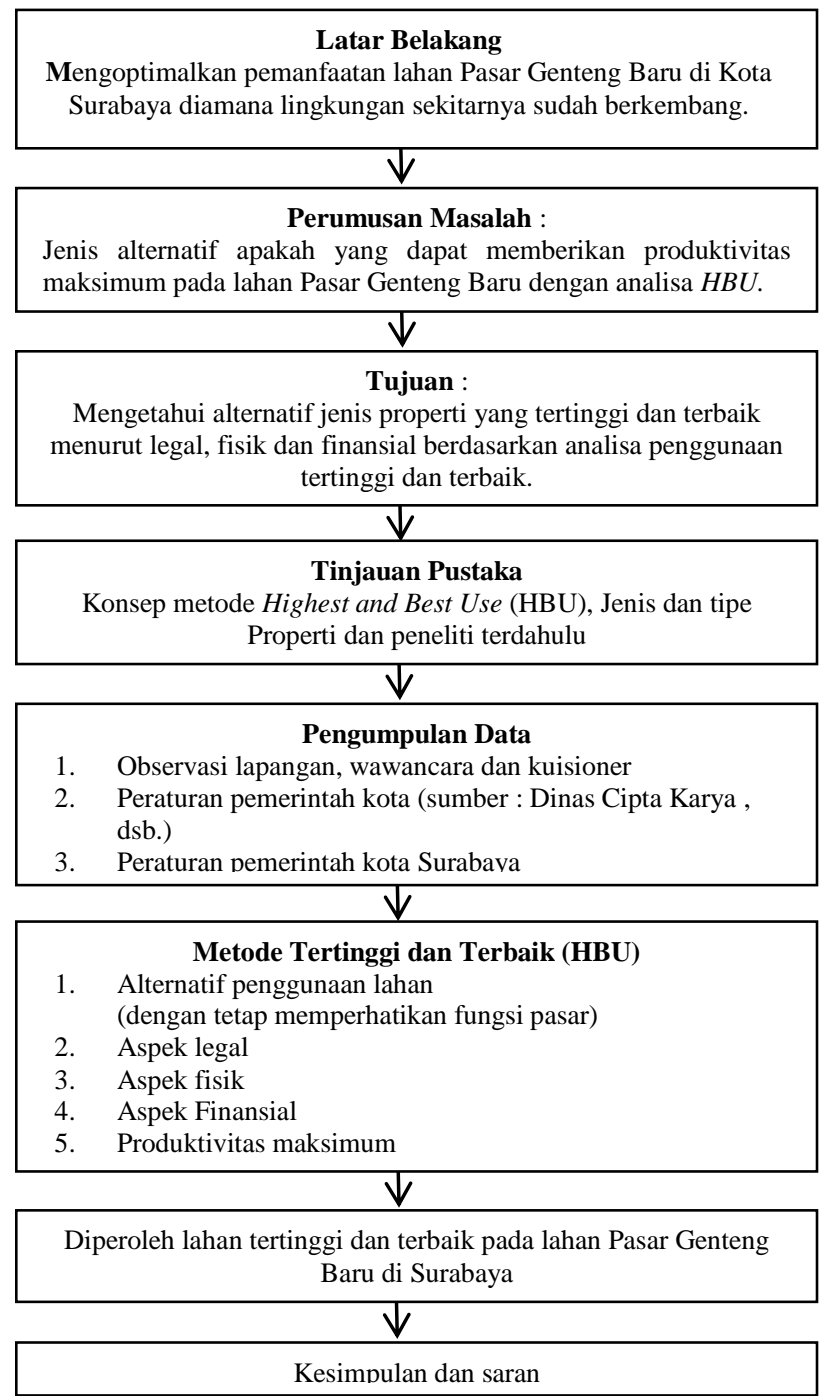

Gambar 2 Bagan Alir Pengerjaan Tugas Akhir

\section{HASIL DISKUSI DAN PEMBAHASAN}

\section{A. Penetapan Alternatif Properti dan Penentuan Nilai Lahan.}

Berdasarkan hasil penyebaran kuisioner kepada para stakeholder pasar Genteng Baru Surabaya diperoleh jenis alternatif yang memungkinkan untuk didirikan pada lahan penelitian yaitu Revitalisasi pasar, Mix used pasar dengan perkantoran, Mix used pasar dengan hotel.Biaya tanah di Jl. Genteng Besar Surabaya didapat dari pendekatan data pasar sebesar Rp. 17.339.387/m².

\section{B. Analisa Aspek Legal}

Pada analisa Highest and Best Use (HBU) perlu dilakukan analisa aspek legal untuk menghindari penyalahgunaan fungsi lahan, sehingga pengembangan yang akan dilakukan sesuai dengan peraturan yang telah ditetapkan oleh pemerintah.
Analisa aspek legal pada lokasi lahan objek penelitian ini mengacu pada Rencana Tata Ruang Wilayah Kota Surabaya (RTRWs) unit pengembangan Jalan Genteng Besar.

1)Zoning atau peruntukan lahan berupa Perdagangan dan Jasa.

2) Klasifikasi jalan merupakan fungsi jalan kolektor sekunder.

3) Garis sempadan bangunan (GSB) untuk sisi depan minimum $3 \mathrm{~m}$, Garis sempadan bangunan (GSB) untuk sisi kanan $6 \mathrm{~m}$, Garis sempadan bangunan (GSB) untuk sisi kiri $4 \mathrm{~m}$, Garis sempadan bangunan (GSB) untuk sisi belakang 6 $\mathrm{m}$.

4) Ketinggian bangunan maksimum 15 lantai.

5) Koefisien dasar bangunan (KDB) maksimum $60 \%$.

6) Koefisien daerah hijau (KDH) minimum $10 \%$.

7) Luas dasar bangunan

8) Luas dasar bangunan $=$ Luas seluruh lahan $\mathrm{x}$ KDB

$$
=4367,205 \mathrm{~m} 2 \times 60 \%
$$$$
=2620,323 \mathrm{~m} 2 \leq 60 \% \text { (memenuhi) }
$$

9) Luas Lantai Bangunan

10) Luas Lantai Bangunan = Luas Seluruh Lahan $\mathrm{x}$ KLB

$$
\begin{aligned}
& =4367,205 \mathrm{~m} 2 \times 900 \% \\
& =39304,845 \mathrm{~m} 2
\end{aligned}
$$

11) Jumlah lantai bangunan maksimum yang dapat dibangun yaitu :

$\frac{\text { Luas Dasar Bangunan Maksimum }}{2620,323 \mathrm{~m} 2}$

$$
=15 \text { Lantai }
$$

Luas lahan yang tidak terbangun

12) Luas lahan yang tidak terbangun adalah selisih luas seluruh lahan dengan luas dasar bangunan yaitu 4367,205 $\mathrm{m} 2-2620,323 \mathrm{~m} 2=1746,882 \mathrm{~m} 2$. Sehingga Koefisien Daerah Hijau diperoleh :

$$
\begin{aligned}
\mathrm{KDH}= & \frac{\text { Luas Lahan Tidak Terbangun }}{\text { Luas Seluruh Lahan }}=\frac{1746,882 \mathrm{~m} 2}{4367,205 \mathrm{~m} 2} \\
& =40 \%>10 \% \text { (memenuhi) }
\end{aligned}
$$

Kesimpulan Aspek Legal

Jadi luas lahan yang tidak terbangun ini memenuhi syarat minimal daerah hijau. Berdasarkan hasil analisa perhitungan diatas maka dapat disimpulkan bahwa lahan seluas 4367,205 $\mathrm{m} 2$ ini dapat dibangun denganbangunan komersial dengan ketinggian lantai 15 lantai, luas dsar bangunan seluas $2620,323 \mathrm{~m} 2$ dan luas lantai bangunan maksimum adalah $390304,8 \mathrm{~m} 2$.

\section{Analisa Aspek Fisik}

Dalam menganalisa dengan metode Highest and Best Use langkah pertama adalah menganalisa kelayakan lahan yang ditinjau dari aspek fisik yang meiputi :

1) Lokasi Lahan

Lokasi lahan objek penelitian berada di Jalan Genteng Besar Surabaya. Lahan ini terletak di tengah kota dan berada di kawasan komersial. Lingkungan yang ada di sekitar lahan objek penelitian merupakan kawasan pemukiman dan fasilitas umum komersial antara lain seperti hotel, perkantoran, pertokoan dan pusat perbelanjaan.

2) Aksesbilitas Lahan

Pengamatan aksesbilitas lahan ditinjau dari segi fungsi jalan dan ketersediaan angkutan umum. Jalan Genteng Besar terletak dipusat kota Surabaya Sehingga Jalan Genteng Besar memiliki aksesbilitas yang sangat baik karena akses masuknya dapat di jangkau dari arah jalan tersebut.

3) Ukuran dan Bentuk Lahan 
Berdasarkan data luasan lahan yang diperoleh, lahan objek penelitian memiliki ukuran $90 \mathrm{~m}$ x $36 \mathrm{~m}$. Lahan ini berbentuk persegi sehingga akan memudahkan dalam proses pembangunan yang direncanakan.

4) Utilitas Lahan

Lahan ini memiliki kelengkapan utilitas kota yang memadai dan dalam kondisi baik. Saluran utilitas yang ada meliputi penyediaan saluran listrik, telepon dan air.

5) Ketersediaan Fasilitas Umum

Lokasi lahan ini berada di pusat kota Surabaya yang mempunyai kelengkapan fasilitas bangunan yaitu saluran listrik, air dan telepon. Selain itu juga tersedia fasilitas lainnya berupa pusat perbelanjaan.

Kesimpulan Aspek Fisik

Berdasarkan hasil pengamatan diatas dapat disimpul-kan bahwa lahan ini dikatakan layak secara fisik karena terletak pada daerah di tengah kota, memiliki aksesbilitas yang mudah dijangkau dengan utilitas lahan yang lengkap. Selain itu, lahan berada diantara kawasan pemukiman dan perkantoran sehingga lahan ini memiliki potensi untuk dikembangkan sebagai properti komersial.

\section{Analisa Aspek Finansial}

Untuk menganalisis Aspek Finansial dari masing-masing alternatif properti dicari nilai value of property dari Net Operating Income (NOI) dibagi dnegan Capitalization Rate (R).

Capitalization rate didapat dari safe rate atau dapat dicari ditambah atau dikurangi dengan tingkat resiko. Safe Rate dapat dicari dnegan rata-rata suku bunga deposito 4 bank besar. Tingkat resiko diasumsikan dengan rata-rata suku bunga deposito bank. Dari hasil pergitungan didapat suku bunga deposito rata-rata adalah 5,72\% sehingga $\mathrm{R}$ bernilai $11,44 \%$.

Untuk perhitungan NOI didapatkan dari pendapatan efektif dikurangi dengan biaya operasional. Sehingga nilai properti dapat diketahui dari hasil analisis aspek finansial. Yeng meliputi biaya investasi, pendapatan, pengeluaran dan aliran kas.

\section{E. Produktivitas Maksimum}

Setelah perhitungan aspek finansial, tahapan selanjut-nya menghitung produktivitas maksimum lahan dengan data nilai property dari hasil analisis finansial, nilai bangunan dari nilai investasi bangunan. Kemudian nilai lahan dicari dnegan mengurangi nilai property dengan nilai bangunan dan nilai lahan per $\mathrm{m} 2$ didapat dari nilai lahan dibagi dengan luas lahan penelitian (Tabel 2).

Tabel 2

Nilai Lahan

\begin{tabular}{|c|c|c|c|}
\hline \multirow[b]{2}{*}{ Uraian } & \multicolumn{3}{|c|}{ Alternatif } \\
\hline & $\begin{array}{c}\text { Revitalisasi } \\
\text { Pasar }\end{array}$ & $\begin{array}{c}\text { Mix Used } \\
\text { Pasar } \\
\text { Tradisional } \\
\text { dengan } \\
\text { Perkantoran }\end{array}$ & $\begin{array}{c}\text { Mix Used } \\
\text { Pasar } \\
\text { Tradisional } \\
\text { dengan Hotel }\end{array}$ \\
\hline Nilai & $\mathrm{Rp}$ & $\mathrm{Rp}$ & $\mathrm{Rp}$ \\
\hline Properti & 115.247 .945 .050 & 433.072.316.098 & 462.537 .510 .748 \\
\hline Nilai & $\mathrm{Rp}$ & $\mathrm{Rp}$ & $\mathrm{Rp}$ \\
\hline Investasi & $\begin{array}{l}169.731 .528 .015 \\
\operatorname{Rp}\end{array}$ & $\begin{array}{l}368.059 .045 .405 \\
\operatorname{Rp}\end{array}$ & $\begin{array}{l}368.810 .658 .951 \\
\mathrm{Rp}\end{array}$ \\
\hline Biaya Tanah & 75.724 .658 .398 & 75.724 .658 .398 & 75.724 .658 .398 \\
\hline Nilai & $\mathrm{Rp}$ & $\mathrm{Rp}$ & $\mathrm{Rp}$ \\
\hline Bangunan & $\begin{array}{l}94.006 .869 .617 \\
\mathrm{Rp}\end{array}$ & $\begin{array}{l}292.334 .387 .006 \\
\operatorname{Rp}\end{array}$ & $\begin{array}{l}293.086 .000 .552 \\
\mathrm{Rp}\end{array}$ \\
\hline Nilai Lahan & 21.241 .075 .433 & 140.737 .929 .091 & 169.451 .510 .196 \\
\hline
\end{tabular}

\begin{tabular}{llll}
\hline \hline Nilai & $\mathrm{Rp}$ & $\mathrm{Rp}$ & $\mathrm{Rp}$ \\
Lahan/m2 & 4.863 .768 & 32.226 .087 & 38.800 .905 \\
Harga Lahan & $\mathrm{Rp}$ & $\mathrm{Rp}$ & $\mathrm{Rp}$ \\
awal & 17.339 .387 & 17.339 .387 & 17.339 .387 \\
Produktivitas & - & $85,85 \%$ & $123,77 \%$ \\
\hline \hline
\end{tabular}

\section{F. Membandingkan nilai lahan per m2 untuk lahan dengan} properti diatasnya

Berdasarkan hasil perhitungan produktivitas maksimum pada tabel 1 didapat nilai lahan tertinggi dengan alternative property mix used pasar dengan hotel dengan nilai lahan $\mathrm{Rp}$ $38.800 .905 / \mathrm{m} 2$. Nilai lahan tersebut lebih tinggi jika dibandingkan dengan nilai lahan awal yaitu $\mathrm{Rp}$ $17.339 .387 / \mathrm{m} 2$.

\section{KESIMPULAN}

Dari pembahasan analisa Highest and Best Use pada lahan pasar Genteng Baru di Jalan Genteng Besar Surabaya didapatkan kesimpulan bahwa lahan seluas 4367,205 m² ini dapat digunakan sebagai bangunan komersial 15 lantai dengan luas dasar bangunan $2620 \mathrm{~m}^{2}$. Ketiga jenis alternatif properti, yaitu revitalisasi pasar, mix used pasar tradisional dengan perkantoran dan mix used pasar tradisional dengan hotel dinyatakan layak. Nilai NPV sebesar Rp 20.490.175.375 dan IRR 15.009\%, mix used pasar dengan perkantoran dengan nilai NPV sebesar Rp 134.003.006.252 dan IRR 18,512\%, mix used pasar tradisional dengan hotel dengan nilai NPV sebesar Rp 162.492.702.303 dan IRR $19,850 \%$.

Dapat disimpulkan bahwa pengembangan lahan sebagai properti komersial mix used pasar tradisional dengan hotel merupakan alternatif penggunaan terbaik bagi lahan di pasar Genteng Baru Surabaya karena memiliki nilai lahan sebesar Rp 38.800.905 $/ \mathrm{m}^{2}$ dengan produktivitas meningkat sebesar $123,77 \%$.

\section{DAFTAR PUSTAKA}

[1] Hidayati dan Harijanto. 2001. Konsep Dasar Penilaian Properti. BPFE: Yogyakarta.

[2] Mubayyinah, M. dan Utomo, C. 2012. Analisa Highest And Best Use (HBU) Lahan " $\mathrm{X}$ " Untuk Properti Komersial. Jurnal Teknik ITS Vol. 1, No. 1, hal. D16-D19.

[3] Anysa, D. dan Utomo, C. 2013. Analisa Highest and Best Use (HBU) Pada Lahan Bekas SPBU Biliton Surabaya. Jurnal Teknik ITS Vol. 2, No. 2.

[4] Krestian, I. dan Utomo, C. 2012. Analisa Peningkatan Nilai Penggunaan Lahan Pasar Keputran di Kota Surabaya. Thesis Jurusan Teknik Sipil ITS : Surabaya

[5] Prawoto, A. 2003. Teori dan Praktek Penilaian Properti. BPFE: Yogyakarta. 